\title{
Eyewitness identification: Effects of suggestion and bias in identification from photographs
}

\author{
ROBERT BUCKHOUT \\ Brooklyn College, C.U.N.Y., Brooklyn, New York 11210 \\ and \\ DARYL FIGUEROA and ETHAN HOFF \\ California State University, Hayward, California 91242
}

\begin{abstract}
141 students were made witnesses to a simulated crime and tested for immediate recall. Seven weeks later, the witnesses were tested for recognition of the perpetrator in a 2 by 2 design which varied the degree of bias in instructions and in the layout of a six-person photospread. Main effects of bias were significant, with a strong interaction effect leading to the highest number of identifications of the perpetrator in the biased photo/biased instruction condition. Suggestivity in photospreads confounds the attribution of a positive identification to the witness's original perception.
\end{abstract}

Would-be "criminals" have been running into psychology classes for decades, committing "crimes" and creating eyewitnesses, eyewitnesses who later prove to be unreliable and inaccurate. Hugo Munsterberg articulated this application of perception research in the salad days of functionalism in his book On the Witness Stand in 1908. But, as compelling as this demonstration of poor recall is, eyewitness testimony continues to be overrated in the courtroom and is the source of many convictions of innocent people (Borchard, 1961). It is a clash of common sense with "expert" judgments, confounded by the fact that the experts know the limits of human perception so well from laboratory research that little well-controlled empirical research on the witness to real or simulated crime exists in the literature.

Buckhout, Alper, Chern, Silverberg, and Slomovits (1974) did research on witnesses to staged crimes, testing both immediate recall and the witness's ability to recognize the culprit in a lineup. Witnesses tended to make a large number of recall errors, to underestimate the weight of the culprit, and to rely on probable height, weight, and age descriptions which resembled published norms rather than the suspect. The relatively few witnesses who were successful in identifying the culprit on a lineup (14\%) had made significantly fewer errors of commission during recall. The lineup, on videotape, was difficult and as unbiased as any test can be. In practice, police lineups frequently are hastily assembled and suffer from biasing factors and suggestion which can lead to mistaken identifications.

As Levine and Tapp (1973) point out, “...the criminal identification process necessarily involves an interaction between sensory and social inputs." The authors describe revenge, expectancy, avoiding looking foolish, reliance on police authority, stereotypes, prejudice evaluation apprehension, conformity, social influence, tester bias, and previewing of a suspect's photo as sources of social psychological bias in lineup identifications-inferring these factors from other experiments which are similar in form (but not content) to a lineup.

Malpass, Lavigeur, and Weldon (1973) described facial recognition as being dependent upon storage in both long- and short-term memory, complicated by the use of both visual and verbal access. Malpass and Kravitz (1969) have shown that white and black witnesses were better able to identify pictures of members of their own race. The authors assume that the main reason for this is more frequent and important experience with members of one's own race. Laughery, Alexander, and Lane (1971) showed that the probability of recognition of previously seen photographs of faces was positively related to duration of original exposure and not affected by pose position or type of photo (color or black and white). The authors report generally high rates of photo recognition-81\% to $97 \%$ in other studies. These accuracy figures contrast sharply with the low accuracy rates encountered in criminal identification work.

Most of the research on facial recognition involves stimulus and test faces on photographs, a factor which limits generalizability to crimes in which a witness encodes his visual perception of a "live" event and is tested either with photographs or a "live" lineup. A serious constraint may lie in the fact that the witness encodes photographic details instead of, or in addition to, facial features. In our study, we chose to simulate a live crime, followed by identification testing with photographs.

The experimental design called for staging an assault in a classroom before a large group of witnesses, measuring immediate recall, waiting several weeks, then administering a lineup of photos which would include the actual culprit. Our main concern was the introduction of biases into the identification testing in 

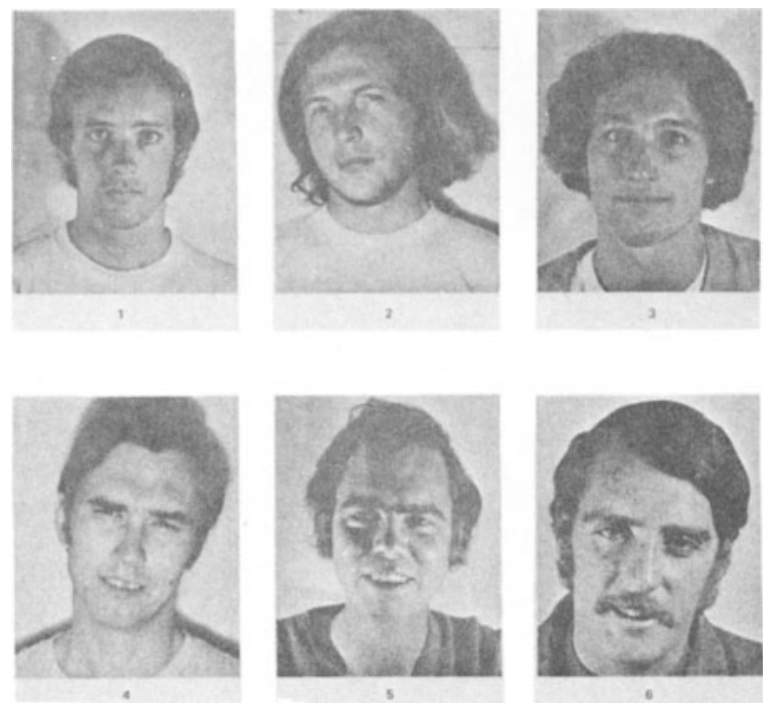

Figure 1. Nonbiased photospread lineup used in testing of recognition by eyewitnesses to an assault (No. 5 was the actual perpetrator).

the form of telling the witness that the culprit was surely in the photospread lineup and in arranging that one photo be highly distinctive. It was predicted that identifications of the culprit would be more numerous under conditions of bias during testing.

\section{METHOD}

\section{Design}

The basic design was a 2 by 2 analysis of variance of recognition performance varying the amount of bias in the instructions and the extent to which the photospread was a leading one. Low-bias instructions preceding the photospread test asked only if the witness recognized any of the persons in the photographs. The high-bias instructions told witnesses that the actual perpetrator was in the lineup. The photospread was made biased by printing the one photo at an angle, with a different expression, etc., to attract attention. The nonbiased photospread was designed to be fair with equivalent photos of all suspects.

\section{Subjects}

The witnesses were 141 undergraduate students in an introductory psychology class at California State University, Hayward; 126 were tested for recognition using the photospread lineup.

\section{Materials}

A short recall questionnaire asking for a physical decription of the suspect, a narrative about the incident, an estimate of the duration of the incident, a statement of confidence, and a signature affirming the truth of the "witness testimony." For the recognition test, each witness received a package containing instructions, a lineup photospread with six photos including the suspect and five other young men of the same age (See Figures 1 and 2) and the Marlowe-Crowne (1960) need for social approval scale. In Figure 1, the nonbiased photospread is shown with roughly equivalent photos used in nonleading photospread conditions. Suspect No. 2 was an innocent bystander who was in
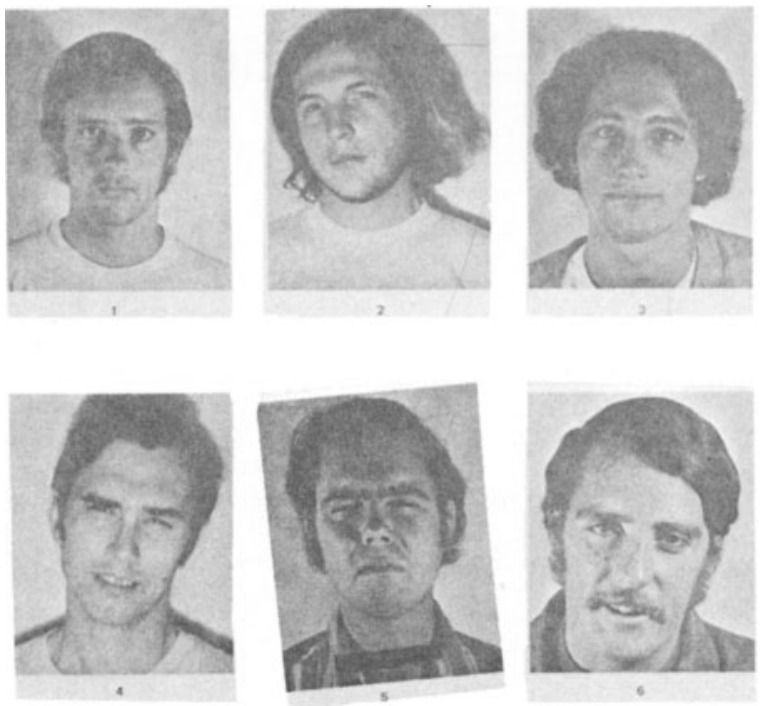

Figure 2. Biased photospread lineup used in testing of recognition by eyewitnesses.

the room at the time of the incident. Figure 2 shows the photospread used in the biased photospread conditions, approximating the hasty tossing in of a recent arrestee's photo into a lineup. Photos of each person were taken in a studio with standard floodlights. The photos were then printed on separate sheets for each witness to view independently.

\section{Procedure}

As a professor lectured to his introductory psychology class, a person entered the room, hesitated, then began to verbally challenge the professor about his grades in another course. Finally, he assaulted the professor, pinning him to a wall, and ran out of the room. The entire incident took $34 \mathrm{sec}$, which we were able to ascertain from the videotape used to record the incident. Immediately afterward, questionnaires were distributed to measure instant recall of details of the incident and the suspect. Seven weeks later, the witnesses were tested on their ability to pick the suspect from a photospread of six and to express their confidence in the extent to which they recognized any members of the lineup. Questionnaire packages reflecting the design conditions were assigned by name to each witness who had been randomly assigned to a cell of the design. These procedures produced recall data in the form of accuracy scores, estimates of height and weight, confidence scores, plus the recognition accuracy scores, need for social approval scores, and grades on an overall comprehensive psychology exam.

\section{RESULTS AND DISCUSSION}

\section{Recall Data}

The recall data summarized in Table 1 tell. the story of generally poor accuracy in the witness's memory for details of the "assault." The total accuracy score achieved was only about $25 \%$ of the possible total-a high rate of errors of omission similar to the results found in Buckhout et al. (1974). The witnesses overestimated the weight of the suspect by $25 \mathrm{lb}$, while they showed reasonable accuracy in estimating his 
height. However, height estimates of a person close to the norm for the population are usually pretty good. Weight being more variable in fact is much harder to guess. We have found in some of our other studies that when witnesses are uncertain about a description, they will often report known population norms or will use their own height and weight as a handy frame of reference (Slomovits, Buckhout, Williams, \& Greenwald, Note 3$)$. This may explain why the age estimates were low and slightly correlated $(r=.18, p<.03)$ with the age of the witnesses, as they perhaps concluded (wrongly) that the suspect must be the same age as a typical college student.

The duration of the incident was overestimated by a factor of almost $2 \frac{1}{2}$ to 1 , reflecting the general tendency of observers to overestimate the passage of time. These overestimates become even more pronounced when a person is under stress. In the present study, we can only presume that some degree of excitement or stress was involved in the witness's reports, but the repeated finding of time overestimation signals caution in taking the time estimates of witnesses seriously.

In testing the various predictor variables against recall accuracy, it was found that witnesses with higher grades on a general psychology exam tended to be more accurate in describing the incident $(r=.38, p<.001)$. There was no relationship between need for social approval and accuracy in recall.

\section{Recognition Accuracy}

An analysis of variance of the recognition accuracy data (measured by confidence in choice) showed significant main effects for biased instructions $(F=5.58$, $\mathrm{df}=1 / 116, \mathrm{p}<.05)$, biased photospreads $(\mathrm{F}=9.05$, $\mathrm{df}=1 / 116, \mathrm{p}<.01)$, and the interaction $(\mathrm{F}=5.60$, $\mathrm{df}=1 / 116, \mathrm{p}<.05)$. Degree of confidence in choosing the actual perpetrator was significantly higher in the biased photospread and biased instruction conditions. As Figure 3 illustrates, the degree of confidence exceeded $50 \%$ only in the condition where both biases operated-a clear indication of the power of social influence on perceptual recognition. In terms of the suspect actually chosen, the percentage of witnesses choosing the perpetrator (Suspect No. 5) parallels the confidence ratings. In the biased instruction/biased photospread

Table 1

Recall Data: Comparison of Average Descriptions by 141 Eyewitnesses With Actual Description of Suspect and Events

\begin{tabular}{lccc}
\multicolumn{2}{c}{$\begin{array}{c}\text { Known Characteristics of } \\
\text { Suspect and Events }\end{array}$} & & $\begin{array}{c}\text { Averaged Descriptions } \\
\text { of Suspect and Events }\end{array}$ \\
\hline Duration of Incident & $34 \mathrm{sec}$ & $81.1 \mathrm{sec}$ \\
Height & $69.5 \mathrm{in.}$ & $70.4 \mathrm{in}$. \\
Weight & $155 \mathrm{lbs}$ & $180 \mathrm{lbs}$ \\
Age & 25 & $\mathrm{yrs}$ & $22.7 \mathrm{yrs}$ \\
Total Possible & $28 \mathrm{pts}$ & $7.4 \mathrm{pts}$ \\
Accuracy Score & & \\
\hline
\end{tabular}
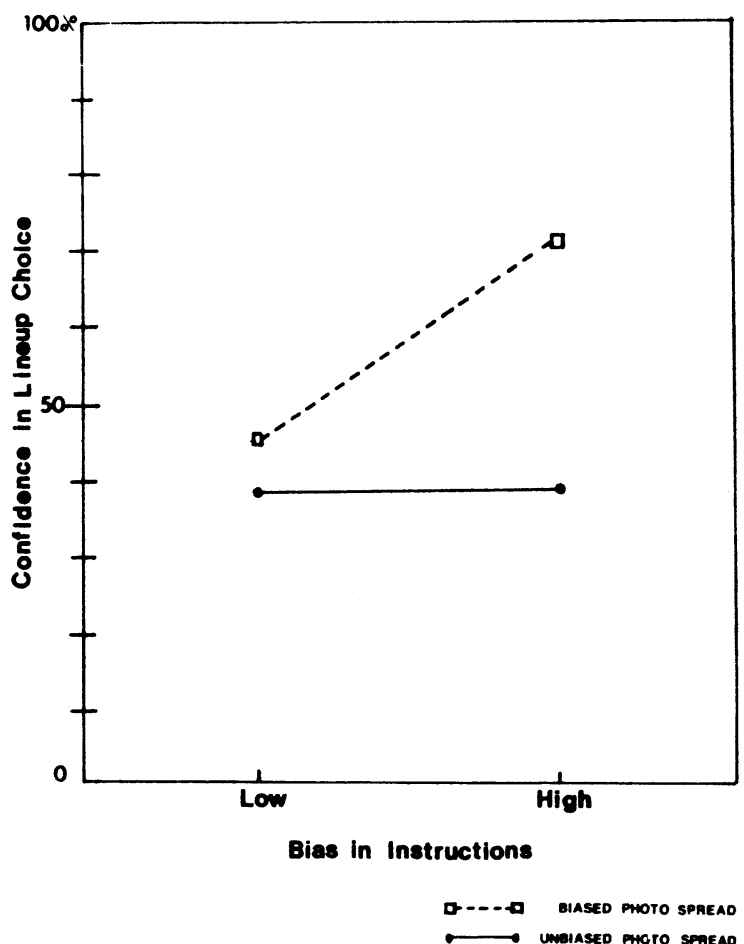

Figure 3. Confidence in lineup choice expressed by ey ewitnesses under conditions varying in degree of bias.

condition, $61.3 \%$ of the witnesses picked the perpetrator. The percentage of witnesses picking the perpetrator in the other conditions averaged around $40 \%$. Overall, $25 \%$ of the witnesses (including the professor victim) mistakenly identified Suspect No. 2, an innocent bystander. When they saw him on the unbiased photospread, the tendency to pick the innocent man was most pronounced.

The correlation between the confidence for lineup choice score and need for social approval was highest for those witnesses who successfully identified the perpetrator $(r=.31, p<.01)$. Thus, the social influence in the testing situation matched up with a personality trait which has been shown to be correlated with acquiescent and conforming behavior (Buckhout, 1965).

In this study, none of the recall data were correlated with confidence scores on the recognition task, but it must be noted that the generally poor recall scores did not vary much among the witnesses. We thus concentrate on the nature of the photospread lineup and its effects on test performance. From the analysis of variance, we note that bias in the layout of the photos accounted for the greatest amount of the variance. We have administered the biased photospread (Figure 3) to groups of nonwitnesses, given only a description of the crime, with the result that even nonwitnesses picked Suspect No. 5 (the distinctive photo) as the most likely perpetrator. They picked the photo well above the chance level, a result similar to that reported by Doob 
and Kirshenbaum (1973). These researchers believe that testing any lineup-videotaped or photographed-on a sample of uninvolved observers who have no knowledge of the offender, would provide a test of the fairness of a lineup. If the nonwitnesses can, to any significant degree, pick out the accused, then scientific evidence would exist on the presence of bias in the lineup. These findings strongly suggest that photographs of the lineup used be made available to defense attorneys prior to trial so that tests for bias might be administered.

In summary, a large group of witnesses who saw a crime and who gave rather inaccurate descriptions went on to make positive identifications from a set of six photos (similar to a lineup) where bias confounded the lineup enough to question whether the identifications resulted from memory of the offender or response to social influence in the lineup recognition test. The hypothesis that identifications of the culprit would be more numerous under conditions of bias during testing was supported. A stacked test can seemingly clarify an otherwise hazy and ambiguous memory of the events around a crime. The only majority consensus in choice of offender occurred in the most biased testing condition. If the picture so biased was that of an innocent man, there is little doubt that he would be mistakenly identified. As Wall (1965) has observed, “...the influence of improper suggestion upon identifying witnesses probably accounts for more miscarriages of justice than any other single factor-perhaps it is responsible for more such errors than all other factors combined." We strongly concur and urge that recognition tests (lineups or photospreads) be tested for possible bias before they are admitted into evidence in court.

\section{REFERENCE NOTES}

1. Buckhout, R. The citizen as a witness. Presentation to the American Psychological Association, September 1, 1974, New Orleans, La.

2. Malpass, R. Racial bias in eyewitness identification. Paper read at meetings of the American Psychological Association, New Orleans, Louisiana, September 1, 1974.

3. Slomovits, M., Buckhout, R., Williams, L., \& Greenwald, M. Toward a test for the eyewitness: Application of signal detection theory to eyewitness identification. In preparation, 1974 Available as Report No.CR-14 from the Center for Responsive Psychology, Brooklyn College, Brooklyn, New York 11210.

\section{REFERENCES}

Borchard, E. M. Convicting the innocent. Hamden, Conn: Archon, 1961.

Buckhout, R. Need for social approval and dyadic verbal behavior. Psy chological Report, 1965, 16, 1013-1016.

Buckhout, R. Eyewitness testimony. Scientific American, 1974, 231, 23-31.

Buckhout, R., Alper, A., Chern, S., Silverberg, G., \& Slomovits, M. Determinants of eyewitness performance on a lineup. Bulletin of the Psy chonomic Society, 1974, 4, 191-192.

Crowne, D. P., \& Marlowe, D. A new scale of social desirability independent of psychopathology. Journal of Consulting Psychology, 1960, 24, 349-354.

Doob, A. N. \& Kirshenbaum, H. M. Bias in police lineups-partial remembering. Joumal of Police Science and Administration, 1973, 1, 287-293.

Laugh ery, K. R., Alexander, J. F., \& Lane, A. B. Recognition of human faces: Effects of target exposure time, target position, and type of photograph. Journal of Applied Psychology, $1971,55,477-483$.

Levine, F. J., \& Tapp, J. L. The psychology of criminal identification. University of Pennsylvania Law Review, 1973, 121, 1079-1131.

Malpass, R. S., \& Kravitz, J. Recognition for faces of own and other "race." Journal of Personality and Social Psychology, $1969,13,330-335$.

Malpass, R. S., Laviguer, H., \& Weldon, D. E. Verbal and visual training in face recognition. Perception \& Psychophysics, 1973, 14, 285-292.

Munsterberg, H. On the witness stand. Essays on psychology and crime. New York: Doubleday (2nd ed.). P. 1915.

Wall, P. Eyewitness identification in criminal cases. Springfield, Illinois: Thoinas, 1965.

(Received for publication April 10, 1975.) 